\title{
HYBRID ELECTRONIC WATT-HOUR METER
}

\author{
J. TRONTELJ, L. TRONTELJ, F. JAN, and M. HROVAT \\ University of Ljubljana, Faculty of Electrical Engineering Tržaška 25, 61000 Ljubljana, Yugoslavia
}

(Received June 11, 1979)

\begin{abstract}
An electronic watt-hour meter in hybrid thick and thin film technology is described. Benefits of combined hybrid technologies are evaluated. Methods for offset voltage and multiplier modulation frequency are given. The hybrid circuit with the $10^{-5}$ linearity for a 0.1 class electricity meter is shown.
\end{abstract}

\section{INTRODUCTION}

A watt - hour meter has to fulfil severe requirements. It has to remain within the declared class of accuracy $1 \%$ of the full scale reading of the measuring range. This corresponds to $10^{-5}$ linearity for a meter with a class of accuracy $0.1 \%$ for the minimum period of 10 years in hostile industrial environments. This is the reason that some people in electrical power distribution do not have confidence in electronic watt-hour meters although these meters can offer many advantages over conventional electromechanical devices.

\section{TECHNOLOGY}

For obvious reasons high quality thin film technology was mandatory. The meter circuit requires a number of resistive elements over $100 \mathrm{kohm}$. Such resistors in thin film technology occupy a large portion of substrate area which would give uneconomical circuit dimensions. One answer to this problem is to use thick film resistors. On the other hand the superior resolution of thin film technology is desirable. The final selection was the combination of thin film interconnections and thick film resistors.

The production process starts by printing and firing thick film resistor layers on 1 in $\times 1$ in $96 \%$ superstrate alumina substrates. Then a thin film conductor layer is deposited in a vacuum chamber followed by chemical etching of conductor lines. IC chips are attached to the substrate by epoxy bonding and circuit interconnections are made by thermocompression or ultrasonic wire bonding. The circuit is encapsulated in a hermetically sealed ceramic-metal flat pack package.

\section{CIRCUIT DESCRIPTION}

A hybrid electronic watt-hour meter is described meeting all requirements for class $0.1 \%$. It consists of two major parts: a threephase multiplier and a voltage to frequency converter for both directions of energy flow (Figure 1).

The circuit is designed to eliminate the need for adjustments by using thin film hybrid technology and is intended for volume production. The most critical amplifier parameter affecting linearity is the offset voltage. In our circuit this problem is solved by using the same chain of amplifiers in the positive and in the negative half period of line voltage reducing the effective offset for several orders of magnitude. This novel approach allowed us to use low cost standard operational amplifiers.

The electronic multiplier is basically a pulse width-pulse height modulator with random modulation frequency. This new approach drastically reduces the required modulation frequency from $20 \mathrm{kHz}$ to $800 \mathrm{~Hz}$ and allows the use of electronic switches and low cost amplifiers with moderate performances.

The voltage to frequency converter is an original combination of up-down integrator and voltage to frequency converter based on constant charge. This

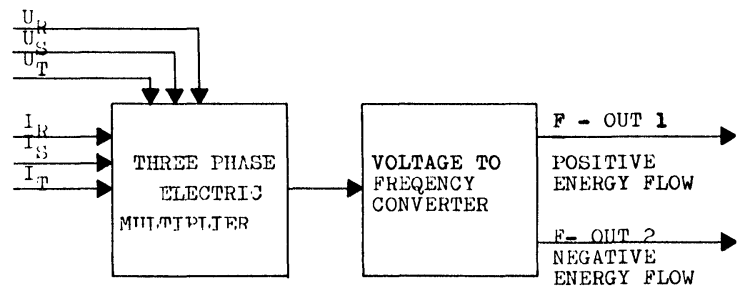

FIGURE 1 Block-diagram of the electronic watt-hour meter 


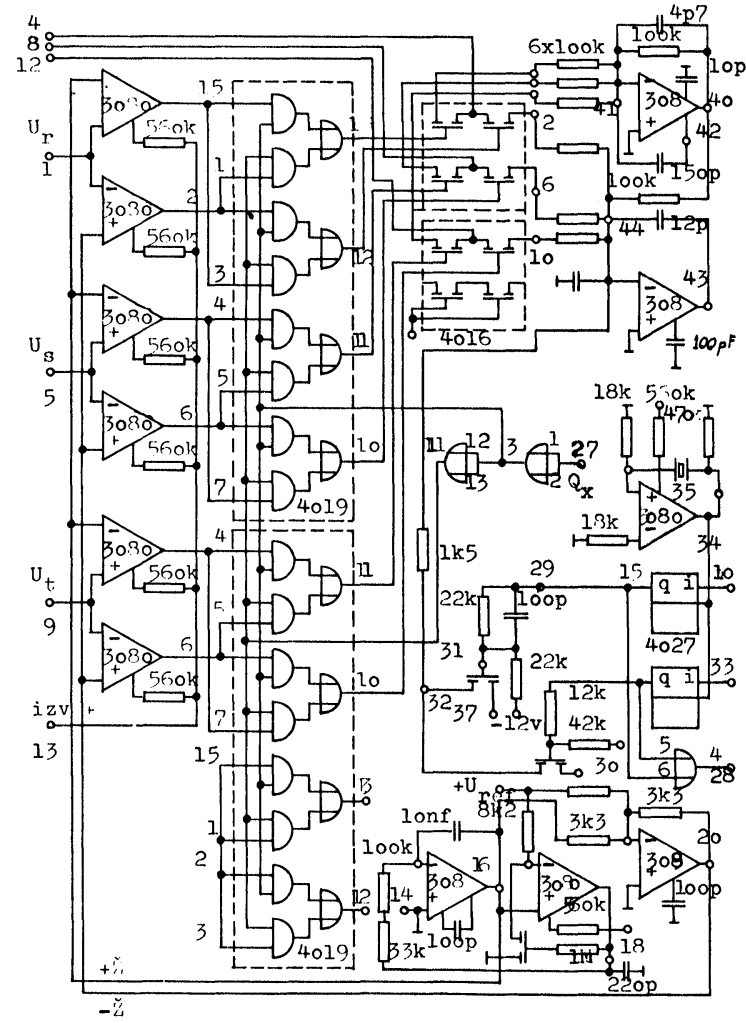

FIGURE 2 Circuit-diagram for the electronic watt-hour meter.

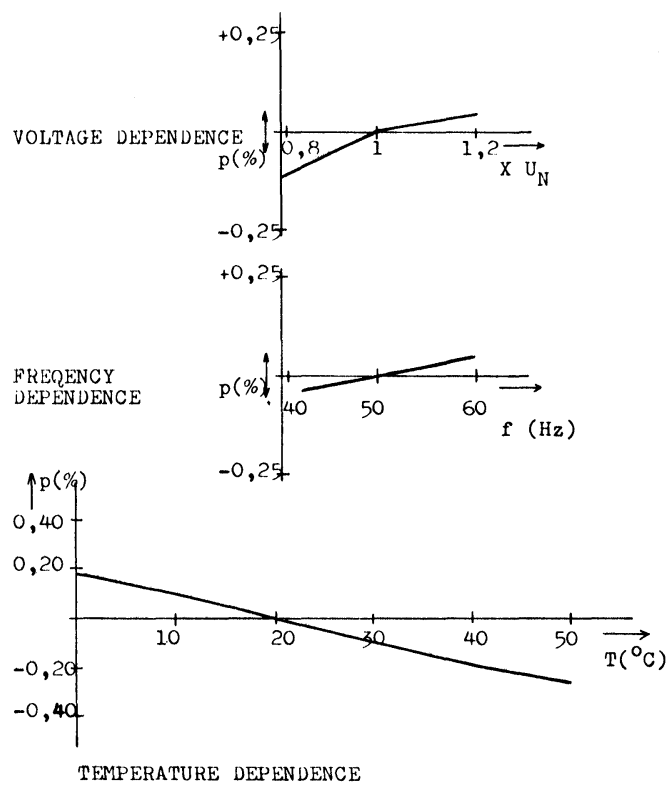

$\cos \varphi=1$

$--\cos \varphi=0,5 \mathrm{~L}$

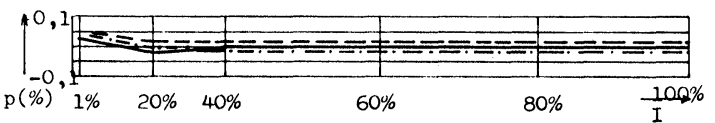

FIGURE 3 Results of measurements on the electronic watt-hour meter.

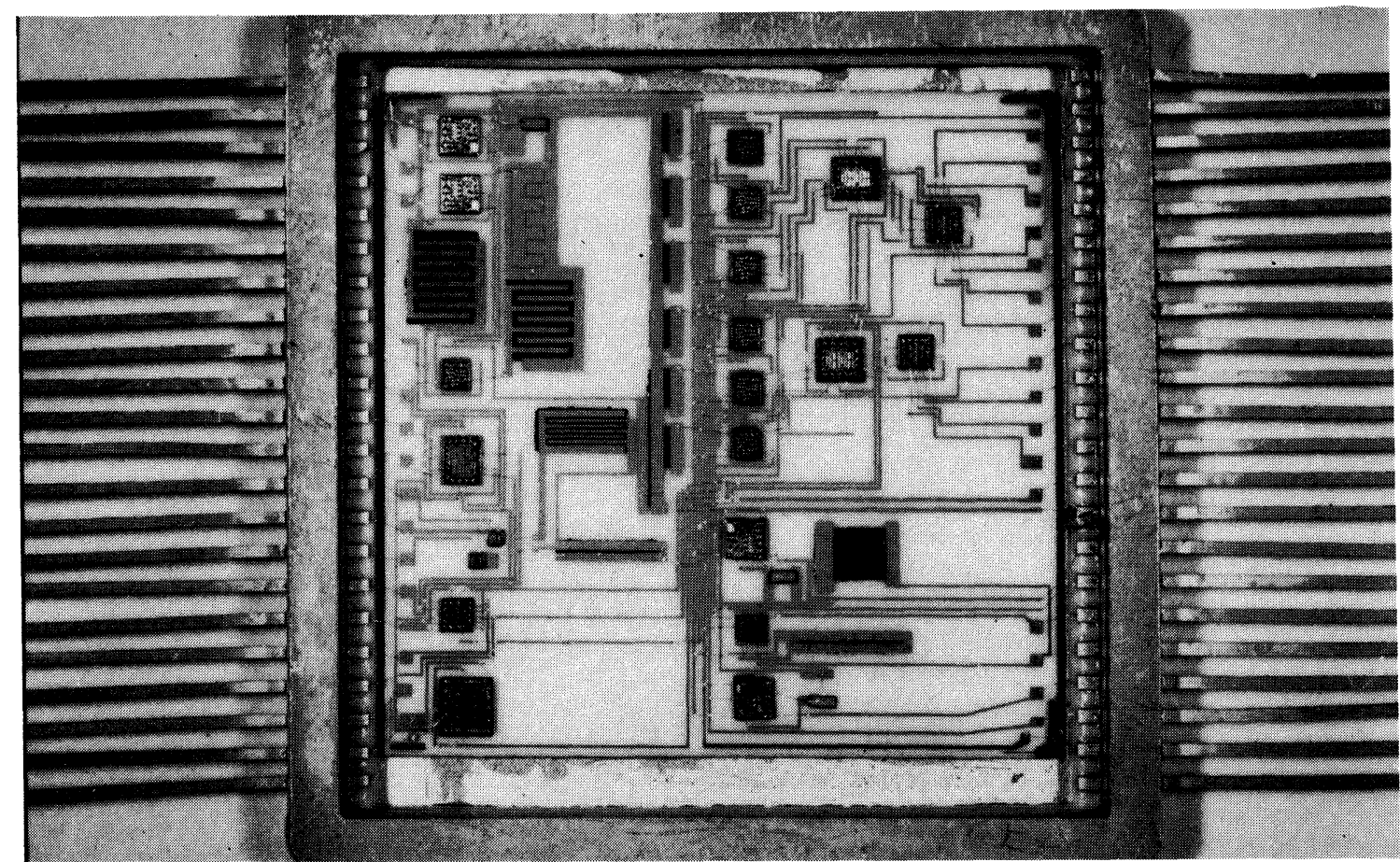

FIGURE 4 Layout of the finished hybrid circuit. 
combination has two notable properties: the accuracy is given by quartz controlled charge and the offset of the integrator is reduced by a known factor for up-down integrators.

The resulting circuit (Figure 2) looks very simple and consists of only 12 operation amplifier and comparator chips and 7 CMOS logic circuit chips. The detailed analysis of the circuit shows that the input energy to output frequency conversion depends only on quartz frequency, reference voltage and resistor ratio. Figure 3 shows some results of the measurements.

The circuit is fabricated on 1 in $x 1$ in ceramic substrate and is hermetically sealed in a professional package (Figure 4). For that reason the circuit is insensible to large electrical and magnetic fields. It survived severe functional and environmental tests at National Bureau of Standards in Yugoslavia and obtained approval.

\section{CONCLUSION}

It is believed that this circuit introduces new concepts of electronic design and technological realisation in the field of electricity measurements. It replaces electromechanical devices having a better performance and compatible price at the higher end of the product line.

\section{ACKNOWLEDGEMENTS}

Authors wish to thank Iskra Elektromehanika for founding the project and final product evaluation. 

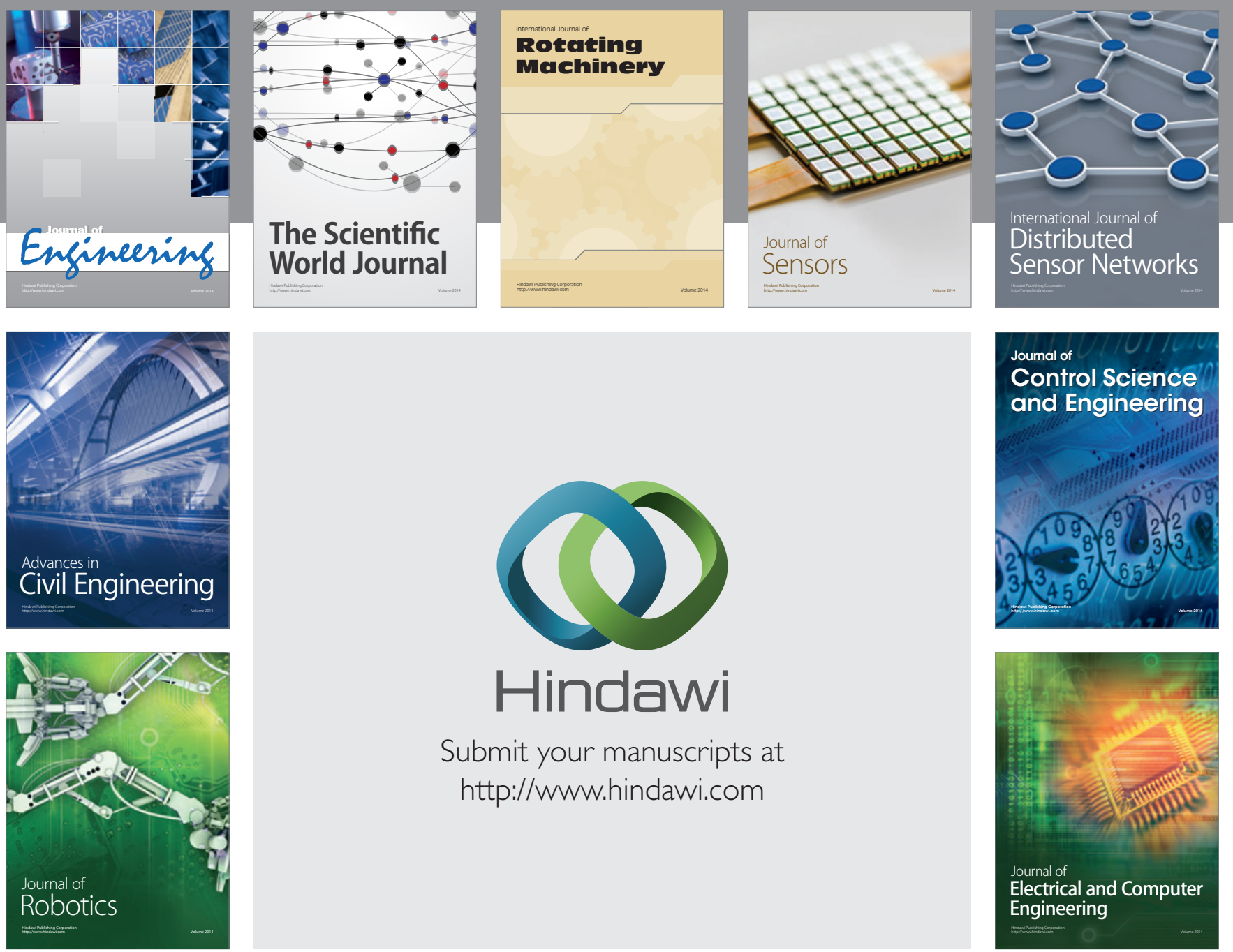

Submit your manuscripts at

http://www.hindawi.com
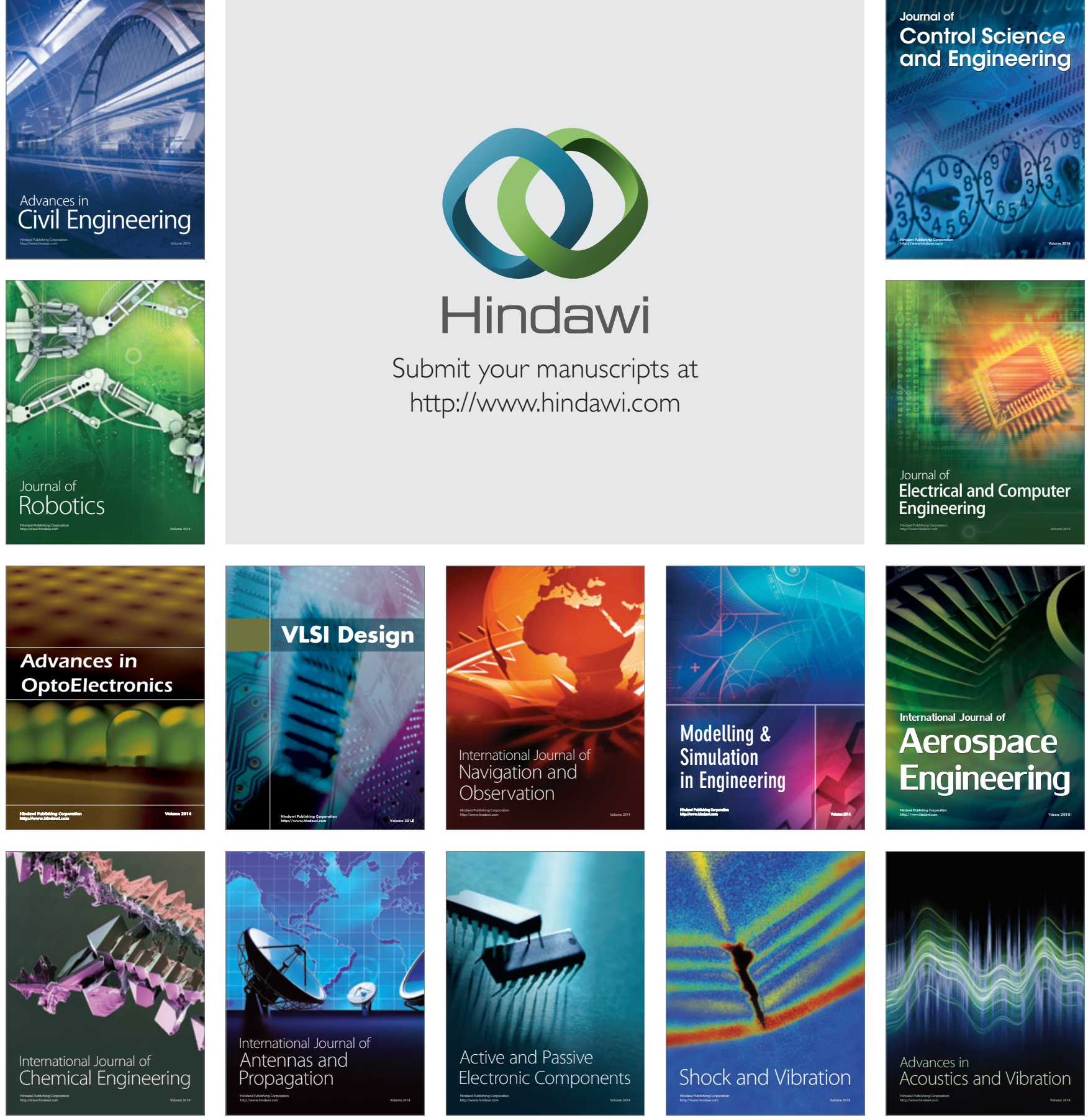